\title{
The physiological consequences of breath-hold diving in marine mammals: the Scholander legacy
}

\author{
Andreas Fahlman* \\ Department of Life Sciences, Texas A\&M University-Corpus Christi, Corpus Christi, TX, USA \\ *Correspondence: andreas.fahlman@tamucc.edu \\ Edited by: \\ David H. Evans, University of Florida, USA \\ Reviewed by: \\ Dan Crocker, Sonoma State University, USA
}

Most of the physiological traits used by marine mammals to perform long and deep breath-hold dives were described in Scholander's seminal paper in 1940. Since then, several studies have provided an improved understanding of the mechanistic basis of the mammalian diving response (Scholander, 1940, 1963; Mottishaw et al., 1999; Fahlman et al., 2011), the aerobic dive limit (ADL) (Kooyman et al., 1980; Butler and Jones, 1997; Davis and Kanatous, 1999; Horning, 2012), and management of respiratory gases (Boutilier et al., 2001; Fahlman et al., 2008a; Hooker et al., 2009; Kvadsheim et al., 2012), but many questions remain. Some widely-accepted ideas actually lack experimental confirmation, and a variety of marine mammal species, potentially novel models for elucidating new diving adaptations, have not been adequately studied. The aim of this Frontiers Special Topic is to provide a synthesis of the current knowledge of the physiological responses that may explain the varied diving behavior of marine mammals. We strove to include contributions that challenge current ideas, and which propose new hypotheses, utilize new experimental approaches, and explore new model species.

Much work has been dedicated to understanding the ADL and how a species can manage its foraging within its ADL. The ADL was originally defined as the length of time an animal could remain submerged before the post-dive blood lactate levels began to increase (Kooyman et al., 1980). The calculated aerobic dive limit (cADL) was later conceived to estimate the maximum duration of aerobic metabolism by dividing the total usable $\mathrm{O}_{2}$ stores by the rate of $\mathrm{O}_{2}$ consumption (metabolic rate, Butler and Jones, 1997). While most species appear to dive well within their cADL, others appear to exceed the CADL on a regular basis (Costa et al., 2001). Horning proposes an interesting method to investigate the plasticity of the functional ADL using constraint lines, which may help improve our understanding of the link between behavior and physiology (Horning, 2012). On a physiological level, it is possible that dives that appear to be beyond the cADL are actually attributable to underestimating the usable $\mathrm{O}_{2}$ stores, or overestimating the metabolic costs of diving and foraging (Hurley and Costa, 2001; Fahlman et al., 2008b; Ponganis et al., 2011). A study suggests that elephant seals possess extreme hypoxia tolerance and make use of their entire blood $\mathrm{O}_{2}$ store during diving (Meir et al., 2009; Ponganis et al., 2011). The use of the spleen to increase hematocrit during diving has been shown to enhance breath-hold capacity in humans (Schagatay et al., 2012) and in marine mammals (Cabanac, 2000; Thornton et al., 2001).
It may be that previous analyses of cADL have missed these sources of usable $\mathrm{O}_{2}$ (Meir and Ponganis, 2009; Ponganis et al., 2011).

Logistical constraints have made it difficult to estimate metabolic rate in foraging animals (Ponganis et al., 2011). Variation in prey density or other environmental factors may alter metabolic costs of foraging. It has been hypothesized that alteration in prey species may affect the nutritional status of the predator (Rosen, 2009). Trumble and Kanatous (2012) argue that the metabolic stoichiometry between $\mathrm{O}_{2}$ and ATP is affected by the lipid composition of the diet. As the lipid composition varies between prey species and seasons, the ingested food may alter the foraging efficiency through changes in the metabolic burden while underwater.

Weingartner et al. (2012) have shown that increased thyroid hormone levels elevate the metabolic rate during diving in harbor seals and result in higher post-dive lactate levels. This suggests that thyroid hormone could be important in modulating metabolic rate to fit the dive conditions. The higher metabolic rate resulted in a more pronounced reduction in heart rate during the dive. This provides an interesting link between endocrine and neural control of the physiological responses during diving. The hyperthyroid animals, with a more extreme diving bradycardia, may be indirect evidence of the $\mathrm{O}_{2}$ conserving effect of the diving response (Weingartner et al., 2012). The diving response is believed to be a conserved physiological trait, which includes diving-induced bradycardia, peripheral vasoconstriction, and altered blood flow distribution (Mottishaw et al., 1999; Fahlman et al., 2011). While our understanding of the central control of the diving response is limited (McCulloch, 2012; Panneton et al., 2012), the bradycardia results in reduced cardiac work. It is not clear whether the reduced work is sufficient to significantly lower the overall metabolic burden, or whether the response serves other purposes. An alternate hypothesis is that the primary role of the diving bradycardia is to regulate the degree of hypoxia in skeletal muscle so that blood and muscle $\mathrm{O}_{2}$ stores can be used more efficiently (Davis and Kanatous, 1999).

If marine mammals generally dive within their cADL, what other physiological constraints may limit diving? Scholander suggested that alveolar collapse (commonly called lung collapse) would limit uptake of $\mathrm{N}_{2}$ and reduce the likelihood of decompression sickness (DCS, Scholander, 1940). However, necropsy reports from mass stranded whales indicated DCS-like symptoms 
(Jepson et al., 2003; Fernández et al., 2005). A more recent study has shown that the gas bubble composition in stranded whales is similar to that from land mammals suffering DCS in experimental dive models (Bernaldo De Quirós et al., 2012). Imaging work in both live and stranded marine mammals indicates that they live with elevated inert gas tensions that cause bubbles to form under certain circumstances (Dennison et al., 2012). This raises some interesting questions: are marine mammals ever at risk of DCS, and if so, could $\mathrm{N}_{2}$ accumulation limit dive performance (Hooker et al., 2009; Kvadsheim et al., 2012; Sivle et al., 2012)? The estimated end-dive $\mathrm{N}_{2}$ levels suggest that a significant proportion of marine mammals should experience DCS symptoms if their responses to elevated $\mathrm{N}_{2}$ are physiologically similar to those of humans and various species of land mammals used in diving simulations (Hooker et al., 2009). Our understanding of the anatomy and physiology of marine mammals is not welldefined in this regard. The DCS model assumptions are based on data from widely different species, which may explain the elevated predictions for marine mammals. A recent study by Costidis and Rommel (2012) provides data on the vascular anatomy in bottlenose dolphins, suggesting that certain adipose tissue compartments may be highly vascularized. The ability to exchange gases in these compartments would vastly alter our understanding of how these species manage gases underwater, and provide interesting research challenges for the future.

Since the initial studies by Scholander in the 1940's, physiologists have been fascinated by the diving traits of marine mammals, and there is a large heritage not only from Scholander, but also from other classical work following this pioneer. While most of the physiological and biochemical traits were suggested Scholander and Irving, few have received as much study as the diving response and $\mathrm{O}_{2}$ management. The contributions to this special topic have shown that the field of diving physiology has recently entered a phase of renewed discovery that is revealing more secrets of the natural responses observed in marine mammals. While there is still a lot more to learn this special topic has focused on work progressing from this heritage, instead of re-inventing knowledge. What is becoming clear is that marine mammals may be a useful model system to understand physiological challenges in extreme environments.

\section{REFERENCES}

Bernaldo De Quirós, Y., GonzalesDiaz, O., Arbelo, M., Sierra, E., Sacchini, S., and Fernández, A. (2012). Decompression versus decomposition: distribution, quantity, and gas composition of bubbles in stranded marine mammals. Front. Physio. 3:177. doi: 10.3389/fphys.2012.00177

Boutilier, R. G., Reed, J. Z., and Fedak, M. A. (2001). Unsteady-state gas exchange and storage in diving marine mammals: the harbor porpoise and gray seal. Am. J. Physiol. 281, R490-R494.

Butler, P. J., and Jones, D. R. (1997). Physiology of diving birds and mammals. Physiol. Rev. 77, 837-899.

Cabanac, A. J. (2000). Blood volume in hooded seals: implications for diving capacity. Can. J. Zool. 78, 1293-1299.

Costa, D. P., Gales, N. J., and Goebel, M. E. (2001). Aerobic dive limit: how often does it occur in nature? Comp. Biochem. Physiol. A Mol. Integr. Physiol. 129, 771-783.

Costidis, A., and Rommel, S. A. (2012). Vascularization of air sinuses and fat bodies in the head of the Bottlenose dolphin (Tursiops truncatus): morphological implications on physiology. Front. Physio. 3:243. doi: 10.3389/fphys.2012.00243

Davis, R. W., and Kanatous, S. B. (1999). Convective oxygen transport and tissue oxygen consumption in Weddell seals during aerobic dives. J. Exp. Biol. 202, 1091-1113.

Dennison, S., Fahlman, A., and Moore, M. J. (2012). The use of diagnostic imaging for identifying abnormal gas accumulations in cetaceans and pinnipeds. Front. Physio. 3:181. doi: 10.3389/fphys.2012.00181

Fahlman, A., Bostrom, B. L., Dillon, K. H., and Jones, D. R. (2011). The genetic component of the forced diving bradycardia response in mammals. Front. Physio. 2:63. doi: 10.3389/fphys.2011.00063

Fahlman, A., Svärd, C., Rosen, D. A. S., Jones, D. R., and Trites, A. W. (2008a). Metabolic costs of foraging and the management of $\mathrm{O}_{2}$ and $\mathrm{CO}_{2}$ stores in Steller sea lions. J. Exp. Biol. 211, 3573-3580.

Fahlman, A., Wilson, R., Svärd, C., Rosen, D. A. S., and Trites, A. W. (2008b). Activity and diving metabolism correlate in Steller sea lion Eumetopias jubatus. Aquat. Biol. 2, 75-84.

Fernández, A., Edwards, J. F., Rodriguez, F., Espinosa De Los Monteros, A., Herraez, P., Castro, P., et al. (2005). 'Gas and fat embolic syndrome' involving a mass stranding of beaked whales (family Ziphiidae) exposed to anthropogenic sonar signals. Vet. Pathol. 42, 446-457.

Hooker, S. K., Baird, R. W., and Fahlman, A. (2009). Could beaked whales get the bends? Effect of diving behaviour and physiology on modelled gas exchange for three species: Ziphius cavirostris, Mesoplodon densirostris and Hyperoodon ampullatus. Respir. Physiol. Neurobiol. 167, 235-246.

Horning, M. (2012). Constraint lines and performance envelopes in behavioral physiology: the case of the aerobic dive limit. Front. Physio. 3:381. doi: 10.3389/fphys.2012.00381

Hurley, J. A., and Costa, D. P. (2001). Standard metabolic rate at the surface and during trained submersions in adult California sea lions (Zalophus californianus). J. Exp. Biol. 204, 3273-3281.

Jepson, P. D., Arbelo, M., Deaville, R., Patterson, I. A. P., Castro, P., Baker, J. R., et al. (2003). Gas-bubble lesions in stranded cetaceans. Nature 425, 575-576.

Kooyman, G., Wahrenbrock, E., Castellini, M., Davis, R., and Sinnett, E. (1980). Aerobic and anaerobic metabolism during voluntary diving in Weddell seals: evidence of preferred pathways from blood chemsitry and behavior. J. Comp. Physiol. B 138, 335-346.

Kvadsheim, P. H., Miller, P. J. O., Tyack, P. L., Sivle, L. L. D., Lam, F.-P. A., and Fahlman, A. (2012). Estimated tissue and blood $\mathrm{N}_{2}$ levels and risk of in vivo bubble formation in deep-, intermediateand shallow diving toothed whales during exposure to naval sonar. Front. Physio. 3:125. doi: 10.3389/fphys.2012.00125

McCulloch, P. F. (2012). Animal models for investigating the central control of the mammalian diving response. Front. Physio. 3:169. doi: 10.3389/fphys.2012.00169

Meir, J. U., Champagne, C. D., Costa, D. P., Williams, C. L., and Ponganis, P. J. (2009). Extreme hypoxemic tolerance and blood oxygen depletion in diving elephant seals. Am. J. Physiol. Regul. Integr. Comp. Physiol. 297, R927-R939.

Meir, J. U., and Ponganis, P. J. (2009). High-affinity hemoglobin and blood oxygen saturation in diving emperor penguins. J. Exp. Biol. 212, 3330-3338.

Mottishaw, P. D., Thornton, S. J., and Hochachka, P. W. (1999). The diving response mechanism and its surprising evolutionary path in seals and sea lions. Am. Zool. 39, 434-450.

Panneton, M. W., Gan, Q., Le, J., Livergood, R. S., Clerc, P., and Juric, R. (2012). Activation of brainstem neurons by underwater diving in the rat. Front. Physio. 3:111. doi: 10.3389/fphys.2012.00111

Ponganis, P. J., Meir, J. U., and Williams, C. L. (2011). In pursuit of Irving and Scholander: a review of oxygen store management in seals and penguins. J. Exp. Biol. 214, 3325-3339.

Rosen, D. A. (2009). Steller sea lions Eumetopias jubatus and nutritional stress: evidence from captive studies. Mammal Rev. 39, 284-306.

Schagatay, E., Richardson, M. X., and Lodin-Sundström, A. (2012). Size matters: spleen and lung volumes predict performance in human apneic divers. Front. Physio. 3:173. doi: 10.3389/fphys.2012.00173

Scholander, P. F. (1940). Experimental investigations on the respiratory function in diving mammals and birds. Hvalråd. Skr. 22, 1-131.

Scholander, P. F. (1963). The master switch of life. Sci. Am. 209, 92-106. 
Sivle, L. D., Kvadsheim, P. H., Fahlman, A., Lam, F.-P. A., Tyack, P. L., and Miller, P. O. (2012). Changes in dive behavior during naval sonar exposure in killer whales, longfinned pilot whales, and sperm whales. Front. Physio. 3:400. doi: 10.3389/fphys.2012.00400

Thornton, S. J., Spielman, D. M., Pelc, N. J., Block, W. F., Crocker, D. E., Costa, D. P., et al. (2001). Effects of forced diving on the spleen and hepatic sinus in northern elephant seal pups. Proc. Natl. Acad. Sci. U.S.A. 98, 9413-9418.

Trumble, S. J., and Kanatous, S. B. (2012). Fatty acid use in diving mammals: more than merely fuel. Front. Physio. 3:184. doi: 10.3389/fphys.2012.00184

Weingartner, G. M., Thornton, S. J., Andrews, R. D., Enstipp, M. R., Barts, A. D., and Hochachka, P. W. (2012). The effects of experimentally induced hyperthyroidism on the diving physiology of harbor seals (Phoca vitulina). Front. Physio. 3:380. doi: 10.3389/fphys.2012.00380

Received: 20 November 2012; accepted: 04 December 2012; published online: 19 December 2012

Citation: Fahlman A (2012) The physiological consequences of breathhold diving in marine mammals: the Scholander legacy. Front. Physio. 3:473. doi: 10.3389/fphys.2012.00473
This article was submitted to Frontiers in Aquatic Physiology, a specialty of Frontiers in Physiology.

Copyright (C) 2012 Fahlman. This is an open-access article distributed under the terms of the Creative Commons Attribution License, which permits use, distribution and reproduction in other forums, provided the original authors and source are credited and subject to any copyright notices concerning any third-party graphics etc. 